\title{
Analysis of Knowledge About Male Breast Cancer Among Higher Education Male Students
}

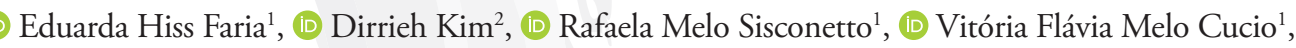

(1) Pedro Paulo Guerreiro dos Reis Ferreira ${ }^{2}$, (1) Bruna Silva Rodrigues Alves ${ }^{3}$, (1) Ígor Mendes Macedo Mendonça ${ }^{1}$,

(1) Maite Rocha Oliveira ${ }^{1}$, (1) Anna Leticia Barbosa Vicente ${ }^{4}$, (1) Jeniffer Cristine Alves ${ }^{4}$, (1) Douglas Reis Abdalla ${ }^{1,4}$

${ }^{1}$ University of Uberaba, Uberaba, Minas Gerais, Brazil (Medicine Student)

${ }^{2}$ Federal University of Triângulo Mineiro, Uberaba, Minas Gerais, Brazil (Medicine Student)

${ }^{3}$ Union of Great Lakes Colleges, Sao Jose do Rio Preto, Sao Paulo, Brazil

${ }^{4}$ Health Courses, Faculty of Human Talents, Uberaba, Minas Gerais, Brazil

\begin{abstract}
Objective: Breast cancer is the most common cancer among women, both in Brazil and worldwide. Breast cancer can also affects men but this constitutes only $1 \%$ of cases and is thus considered rare, and for this reason is little studied. Statistics indicate an increase in its incidence with an estimate of new cases in recent years. This study aims to analyze the knowledge of higher education students in relation to breast cancer in men. the knowledge of higher education students in relation to breast cancer in men.

Materials and Methods: exploratory study with a quantitative approach. 299 male students participated in the study. Data collection took place through semi-structured questionnaires, completed by students from pure science, human sciences and health at a higher education institution.

Results: Regardless of the area of undergraduate study, $65.9 \%$ of the volunteers reported not knowing about breast cancer in men. Regarding predisposing factors for the development of breast cancer, $77.3 \%$ reported not knowing about these while $68.9 \%$ reported not knowing about breast self-examination. However, $67.6 \%$ believe that breast cancer in men can be prevented. Worryingly, $62.5 \%$ reported that they only seek medical assistance when becoming ill.

Conclusion: Evidence from this study suggests that higher level undergraduates have limited knowledge about breast cancer in men. Only one third knew that male breast cancer was possible. Even smaller proportions knew of the predisposing factors for breast cancer, how to perform self-examination and about diagnosis. These latter factors, when combined with a tendency to seek medical help only when ill, suggests a short-fall in health knowledge which should be corrected.
\end{abstract}

Keywords: Breast cancer, masculine, health promotion, men's health

Cite this article as: Faria EH, Kim D, Sisconetto RM, Melo Cucio VF, dos Reis Ferreira PPG, Rodrigues Alves BS, Mendonça ÍMM, Oliveira MR, Vicente ALB, Alves JC, Abdalla DR. Eur J Breast Health 2021; 17(4): 333-340.

\section{Key Points}

- Higher education students show limited knowledge about breast cancer in men.

- Health care for men needs more attention.

- Young adults in professional training areas other than health care have limited understanding of breast cancer in men.

\section{Introduction}

Breast cancer (CA) is a very heterogeneous disease, with a wide variety of clinical and prognostic developments. Globally, breast CA is the fifth greatest cause of death from cancer - totaling 684,996 deaths - considering both sexes and all ages (1). Even when considering non-melanoma skin CA, female breast CA still ranks first in the estimated number of prevalent cases $(5$ years) worldwide for all ages. For men, the disease is rare, and the lifetime risk of breast CA is approximately 1:1000, with this risk being 1:8 for women (2). In 2018, about 2,550 men were diagnosed with breast CA in the United States and it accounted for 480 deaths. In comparison, there were approximately 266,120 new cases of women with breast CA and approximately 40,920 deaths (3). 
In Brazil, data from the National Cancer Institute José Alencar Gomes da Silva (INCA) estimate that 66,280 new cases of breast CA appear each year between 2020 and 2022 (4). Currently, little is known about the incidence of breast CA in men, few records are found concerning such pathology, and studies, due to the low prevalence, often do not receive incentives. Thus, it is not even possible to find estimated incidence/mortality rates in the GLOBOCAN (2020) reports (1). In Brazil, however, according to a study done in 2018, among the 17,763 deaths from breast CA, 17,572 were female and 189 male (5).

The most common histological type in women is epithelial cell carcinoma, which is divided into in situ and invasive. The most common carcinomas are ductal and lobular carcinomas, with luminal subtypes A and B being the most frequent and with the best prognosis (6-9). Concerning breast tumors in men, these subdivisions have no relevant impact, but it is known through research of gene expression that there may be genetic aberrations and molecular types not seen in women, thus worsening their prognosis (10). Several risk factors contribute to the development of male and female breast CA. According to INCA, with data from 2019, age over 50 is considered the most important among the risk factors for both sexes. Another important factor is related to the family history of CA in first-degree relatives, where the chances of development increase by 2.5 times (11). Amongst genetic factors, it is important to highlight mutations in the breast $C A$ genes, and those in BRCA2 are closely associated with high-risk tumors, with worse prognosis, unlike the BRCA1 type mutations, that indicate lower rates of morbidity and mortality. In men the estimates for the development of male breast CA range from $1 \%$ to $5 \%$ for men with BRCA1 mutations and from $5 \%$ to $10 \%$ for men with BRCA2 mutations (12).

According to the data published by Carvalho Neto et al. (11), both men and women who drink more than $10 \mathrm{~g}$ /day of alcohol have a $16 \%$ increased risk of developing breast CA. Other predisposing risk factors include exposure to radiation, administration of estrogen, and diseases associated with hyperestrogenism, such as cirrhosis. Obesity can also increase the risk of breast CA in men, possibly due to hormonal mechanisms. There is data suggesting that black men are at greater risk than non-Hispanic white men (13). Testosterone levels also dictate an important increase in the risk of developing the disease, as men have 20 times more androgenic hormone compared to postmenopausal women (14). Klinefelter syndrome, characterized by hypogonadism and low testosterone levels, an anomaly generated by a prototype XXY sex chromosome appears to convey a much increased risk of male breast CA. According to a study by Swedish Cancer Registry, the estimated risk of breast CA among men with Klinefelter syndrome is increased by up to 50 times, compared to unaffected men (15).

There are controversies regarding the prevention and screening of male breast CA. Some authors claim that such malignancies can be prevented through adequate nutritional care and physical activities, but that, in addition to these habits, the best from of prevention is the early diagnosis of the disease, which, as in women, when done in the early stages, substantially increases the chances of curative treatment (16).

This diagnosis, unfortunately, does not happen frequently, since it is not a prevalent disease in men, because they are unaware of the because of the prejudice and stigmatization that characterize breast $\mathrm{CA}$ as a disease of women. Furthermore, there are no national or international guidelines from health agencies to guide health professionals on how to properly prevent male breast cancer, making the condition an undernoticed public health issue (17). As men have less breast tissue than women, nodules suggestive of a tumor are more easily noticed, but they spread more easily and quickly, causing them to be noticed in already advanced conditions (18).

Management of male breast CA is the same as for female CA. Therapeutic interventions include surgery, radiotherapy and systemic therapies, which include chemotherapy and endocrine treatments (19).

The aim of this study was to investigate the extent of knowledge about male breast CA among men in higher education, and also to compare the degree of knowledge about this subject among students of different subjects including human science, pure science and health science, at the Higher Education Institution of Uberaba Faculty of Human Talents.

\section{Materials and Methods}

The basic function of a good research project is to facilitate a robust comparison between the different variables of the groups of subjects included in the study. Thus, in order to seek reliable results, this cross-sectional study was adopted with an observational descriptive character. The study was carried out via a questionnaire completed by undergraduate students studying health science, pure science and humanities fields at the Faculty of Human Talents (FACTHUS), located in the city of Uberaba, Minas Gerais, Brazil.

Eligible subjects included all male undergraduate students in these subjects. Male students were randomly selected from the FACTHUS population. Inclusion criteria were male students enrolled in this faculty and who agreed to complete the questionnaire. Exclusion criteria were those who were outside the pre-established study population and those who were chosen at random but refused to participate.

Three questionnaires were used. The first collected sociodemographic data including marital status, age, maternal education, family income and the area of the undergraduate course. The second questionnaire assessed life habits, including the age of sexual initiation, use of drugs, dietary supplements and steroid drugs, as well as alcohol and tobacco consumption. The third questionnaire investigated the extent of knowledge about breast CA in men, including general knowledge of male breast CA, if treatment is available, predisposing factor for developing breast $\mathrm{CA}$ in men, genetics and heredity issues, if the respondent was aware of family cases, aspects of prevention and the habit of conducting routine medical consultations.

The statistical analysis was carried out using Excel 2013 for Windows (Microsoft - EUA). Data was analyzed using SPSS, version 20 (IBM Inc., Armonk, NY, USA). The Shapiro-Wilk Test was used to verify the normal distribution of the quantitative variables. The continuous variables, which present normal distribution, were expressed in mean \pm standard error of mean, for the multiple comparisons, the ANOVA test and Tukey's test were used. Student's t-test was used for single comparisons. Variables that did not have normal distribution were expressed in median and range, for the multiple comparisons, the Kruskal-Wallis and Dunn's tests were used. For single comparisons, Mann-Whitney's test was used. For the comparisons of frequencies 
and percentages, the chi-square test was used. The significance level was set at $5 \%(\alpha=0.05)$.

This project was submitted to the Research Ethics Committee with Human Beings of the FACTHUS under registration number 05/2018, as well as the use of the free and informed consent term to carry out the project and apply the questionnaires to people as required. Resolution 466/2012 of the National Health Council on ethical issues in research with human participants, from the Ministry of Health of the Federative Republic of Brazil.

\section{Results}

The sample consisted of 299 male undergraduate students aged between 17 and 50 years. The evaluated students were from the areas of humanities, pure science and health sciences. The proportions of the cohort by education area were: $56.2 \%$ from pure science; $26.1 \%$ from humanities; and $17.7 \%$ from health sciences. The sociodemographic data of the participants is shown in Table 1. It shows the sample distribution in relation to the median age of 24.0 , with a range of 33 . Regarding marital status, most of the sample (75.9\%) was single, while the most common maternal education level was high school/technical education (41.8\%). The majority of respondents (68.2\%) reported a family income of at least two minimum wages.

Regarding lifestyle habits, respondents reported that the onset of sexual activity was on average at 14.2 years of age, with a minimum age

Table 1. Distribution of the sample in relation to age, marital status, maternal education, family income and area of the undergraduate course

\section{Variables}

n (\%)

Median age (range), years $24(33)$

\section{Marital status}

Single

Married

$70(23.4)$

No data

\section{Maternal education}

Fundamental

Medium / Technical

$125(41.8)$

Graduation

57 (19.1)

Postgraduate studies

$17(5.7)$

No data

38 (12.7)

Family income

Up to 1 salary

Between 1 and 2 Salaries

58 (19.4)

Above 2 wages

204 (68.2)

No data

$25(8.4)$

Undergraduate area

Pure Sciences

$168(56.2)$

Humanities

78 (26.1)

Health Sciences

$53(17.7)$ of 9 and a maximum of 19 (Table 2). In relation to the use of drugs, supplements and steroids $71.2 \%$ report no use. Regarding alcohol and cigarette consumption, $57.2 \%$ were users.

In this sample of male higher education students there was a worrying deficit in knowledge about male breast CA (Table 3). Almost twothirds $(65.9 \%)$ were unaware that male breast cancer exists. In terms of treatment of male breast CA, $66.9 \%$ thought that it was possible to successfully treat the disease while $32.1 \%$ thought that there was no cure. Regarding predisposing factors in the development of breast cancer, most respondents $(77.3 \%)$ thought that there were no predisposing factors.

In this cohort, $58.2 \%$ thought that male breast cancer had a hereditary element and $52.2 \%$ reported no history of breast cancer in their families. Regarding breast self-examination, $68.9 \%$ said they had no knowledge of how to self examine, and $76.6 \%$ of participants reported not knowing the signs and symptoms of male breast cancer.

In terms of breast cancer prevention, $67.6 \%$ reported having knowledge of appropriate preventative measures while $23.7 \%$ answered they had no knowledge. Of the 299 participants, $62.5 \%$ report that they only go to a medical appointment when they become ill.

Comparing the mean ages of the students studying different subject areas showed that students of pure sciences tended to be significantly older $(\mathrm{p}<0.0001$; Table 4$)$. These students were significantly more likely to be married $(29.8 \% ; \mathrm{p}=0.01)$ but for the three subject areas most male students were single: pure science $69.6 \%$ single; humanities $83.3 \%$ single; and health sciences $84.9 \%$ were single.

Most participants reported that their mothers had achieved high school/technical education (Table 4). The proportion of mothers with elementary education was higher in the students from the humanities $(26.9 \%)$, compared to graduate courses, the percentage of parents is higher in the health course $32.1 \%(\mathrm{p}=0.006)$. Students from the pure sciences tended to have greater family income $(>2$ minimum wages) than students from the other two subject areas (72\% vs $64.1 \%$ and $62.3 \%)$. Students from the humanities were more likely to have a family income below one minimum salary (9\%) compared to either the students from pure sciences $(2.4 \%)$ or health sciences $(1.9 \%)$.

Table 2. Distribution of the sample in relation to life habits

\section{Questions}

Beginning of sexual activity (years)

Mean (min-max)

$14.2(9-19)$

n (\%)

Use of drugs, supplements and steroids

Yes

$83(27.8)$

No

$203(71.2)$

No data

$3(1.0)$

Alcohol and cigarette consumption

Yes

$171(57.2)$

Not

$128(42.8)$ 
Across the different groups of students the reported age of initiating sexual activity varied significantly (Table 5). Reported use of drugs and supplements was low in each group, with the rates being $14.1 \%$ in the humanities, rising to $30.2 \%$ in the health sciences and $33.3 \%$

Table 3. Distribution of the sample in relation to knowledge about Male Breast Cancer

\begin{tabular}{lc} 
Questions & Answers \\
\hline What is male breast cancer & $\mathbf{n}(\%)$ \\
Yes & $102(34.1)$ \\
No & $197(65.9)$ \\
Breast cancer can be cured & \\
Yes & $200(66.9)$ \\
No & $96(32.0)$ \\
No data & $3(1.0)$
\end{tabular}

Influencing factors in the development of breast cancer

Yes 66 (22.1)

No $231(77.3)$

No data

Hereditary

Yes

No

$122(48.8)$

No data

Family history of breast cancer

Yes

No

No data

Knowledge about self-examination

Yes

No

No data

Signs and symptons

Yes

No

No data

Every tumor is cancer

Yes

No

$132(44.1)$

No data

Yes

No

No data

$187(62.5)$

When sick

$88(29.4)$

Annually

$24(8.0)$

No data in the pure sciences. This pattern was different and significantly different between the groups for use of alcohol and tobacco with health sciences students reporting the most widespread use $(77.4 \%)$ followed by the humanities $(60.3 \%)$ and the lowest reported usage was in the pure sciences students (49.4\%).

When asked about knowledge of Male Breast Cancer, 30.4\% of respondents in pure science, $37.2 \%$ in the humanities and $41.5 \%$ in the health sciences knew of male breast cancer, results that were not different $(p=0.263)$. Similarly knowledge of the heredity and prevention of breast cancer were also not statistically significant (Table 6). With regard to breast cancer having a cure, $84.9 \%$ of health sciences students knew that it was possible, while this proportion fell to $79.5 \%$ in the humanities and $55.4 \%$ in the pure sciences. In terms of predisposing factors for the development of breast cancer most students had no knowledge, with less than a third of health sciences and humanities students understanding that predisposing factors exist; significantly fewer pure sciences students knew of the existence of these factors $(\mathrm{p}=0.005)$.

More than half of the health sciences and pure sciences students reported a family history of breast cancer $(54.7 \%$ and $51.8 \%$, respectively). Only a minority of students knew about selfexamination; $19.6 \%, 34.6 \%$ and $35.8 \%$ in the pure sciences, humanities and health sciences student groups respectively. With regard to the signs and symptoms of breast cancer, the three areas showed that most students did not have knowledge of this (Table $6)$. When asked if every breast tumor is considered a cancer, most students of pure science (61.9\%) responded "yes" while significantly fewer in the health sciences and humanities thought this was true (37.7\% and $29.5 \%$, respectively; $\mathrm{p}<0.0001)$. Finally, with regard to medical consultations, most students reported that they only seek to consult when they are ill, with $73.8 \%$ of pure sciences students, $57.7 \%$ of humanities students and $34 \%$ of health sciences students giving this response.

\section{Discussion and Conclusion}

Our main results show that most volunteers reported not knowing about breast cancer in men, regardless of the area of study, pure sciences, humanities or health sciences. Regarding the influential factors for the development of breast cancer, most reported not knowing about these factors. Also, the male respondents in this study reported not knowing about breast self-examination, but they believed that there are ways to prevent breast cancer. However, most respondents only sought medical help when unwell.

Greater knowledge about the pathology, dissemination of information through the media and high awareness of female breast CA in primary health care services means that female breast tumors tend to be discovered in less advanced stages. This is not happening with male breast CA, but a similar programme would be important to reduce the psychosocial suffering of those who have the diagnosis, in addition to disseminating knowledge. (19).

This study confirms earlier findings, which showed that men have little knowledge about male breast CA (20). According to the National Institute of Cancer, the incidence and prevalence of male breast cancer in Brazil is low, and due to this, there is little scientific and general interest in the subject. In addition, the fact that the literature on breast cancer is mostly aimed at the disease in women contributes to misinformation among men. For example, breast cancer prevention 
campaigns and instructions on how to perform self-examination are directed at the female population, as seen in the October Rose, which focuses on the fight against breast cancer and encouraging the participation of the population in combating this disease (21).

Most of the interviewed participants demonstrated that they were unaware of what male breast cancer is, as well as being unaware of the signs and symptoms and predisposing factors, confirming a lack of general knowledge, even in students of the health sciences. The same was observed by Thomas, when 28 men with no personal history of breast cancer, and with at least one relative of maternal blood with the disease were interviewed (19). Approximately $80 \%$ were unaware of the possibility that they could develop the disease, and despite being at high risk, all participants reported that the family unit never discussed the subject. Still, the majority reported that they did not know how to identify signs and symptoms of the condition, except for nodules in the breast.

Table 4. Distribution of the sample in relation to age, marital status, maternal education, family income in the different areas of knowledge

\begin{tabular}{|c|c|c|c|c|}
\hline Variables & Exact sciences & Human sciences & Health sciences & p-value \\
\hline Mean age (SEM) & $26.7(0.56)$ & $24.0(0.53)^{*}$ & $23.6(0.48)^{*}$ & 0.0001 \\
\hline \multicolumn{5}{|l|}{ Marital status, n (\%) } \\
\hline Single & $117(69.6)$ & $65(83.3)^{*}$ & $45(84.9) *$ & \multirow{3}{*}{0.010} \\
\hline Married & $50(29.8)$ & $12(15.4)$ & $8(15.1)$ & \\
\hline No data & $1(0.6)$ & $1(0.8)$ & $0(0.0)$ & \\
\hline \multicolumn{5}{|l|}{ Maternal education, n (\%) } \\
\hline Fundamental & $31(18.5)$ & $21(26.9)$ & $10(18.9)$ & \multirow{5}{*}{0.006} \\
\hline Medium/Technical & $69(41.1)$ & $34(43.6)$ & $22(41.5)$ & \\
\hline Graduation & $25(14.9)$ & $15(19.2)$ & $17(32.1)^{\#}$ & \\
\hline Postgraduate studies & $13(7.7)$ & $1(1.3)$ & $3(5.7)$ & \\
\hline No data & $30(17.9)$ & $7(9.0)$ & $1(1.9)$ & \\
\hline \multicolumn{5}{|l|}{ Family income, n (\%) } \\
\hline Up to 1 salary & $4(2.4)$ & $7(9.0)$ & $1(1.9)$ & \multirow{4}{*}{0.0001} \\
\hline Between 1 and 2 salaries & $20(11.9)$ & $19(24.4)$ & $19(35.8)^{\#}$ & \\
\hline Above 2 wages & $121(72.0)$ & $50(64.1)$ & $33(62.3)$ & \\
\hline No data & $23(13.7)$ & $2(2.6)$ & $0(0.0)$ & \\
\hline
\end{tabular}

* $p<0.05$ vs volunteers from exact courses.

" $\mathrm{p}<0.05$ vs volunteers from exact and human courses.

SEM: Standard error of mean, n: Number

Table 5. Distribution of the sample in relation to life habits in different areas of knowledge

\begin{tabular}{|c|c|c|c|c|}
\hline Questions & Exact sciences & Human sciences & Health sciences & p-value \\
\hline $\begin{array}{l}\text { Beginning of sexual activity } \\
\text { mean (SEM) years }\end{array}$ & $13.7(0.21)$ & $15.2(0.22)^{*}$ & $14.6(0.32)$ & 0.0001 \\
\hline \multicolumn{5}{|c|}{ Use of drugs, supplements and steroids, n (\%) } \\
\hline Yes & $56(33.3)$ & $11(14.1)^{\$}$ & $16(30.2)$ & \multirow{3}{*}{0.012} \\
\hline No & $109(64.9)$ & $67(85.9)$ & $37(69.8)$ & \\
\hline No data & $3(1.8)$ & $0(0.0)$ & $0(0.0)$ & \\
\hline \multicolumn{5}{|c|}{ Alcohol and cigarette consumption, n (\%) } \\
\hline Yes & $83(49.4)$ & $47(60.3)$ & $41(77.4)^{*}$ & \multirow{2}{*}{0.001} \\
\hline No & $85(50.6)$ & $31(39.7)$ & $12(22.6)$ & \\
\hline
\end{tabular}

${ }^{*} \mathrm{p}<0.05$ vs volunteers from exact courses.

${ }^{5} p<0.05$ vs volunteers in the exact and health courses.

SEM: Standard error of mean, n: Number 
Table 6. Distribution of the sample in relation to the knowledge about male breast cancer in the different areas of knowledge

\begin{tabular}{|c|c|c|c|c|}
\hline Questions & Exact sciences & Human sciences & Health sciences & p-value \\
\hline \multicolumn{5}{|l|}{ What is male breast cancer, $n(\%)$} \\
\hline Yes & $51(30.4)$ & $29(37.2)$ & $22(41.5)$ & \multirow{2}{*}{0.263} \\
\hline No & $117(69.6)$ & $49(62.8)$ & 31 (58.5) & \\
\hline \multicolumn{5}{|l|}{ Breast cancer can be cured, n (\%) } \\
\hline Yes & $93(55.4)$ & $62(79.5)^{*}$ & $45(84.9)^{*}$ & \multirow{3}{*}{0.0001} \\
\hline No & $74(44.0)$ & $15(19.2)$ & $7(13.2)$ & \\
\hline No data & $1(0.6)$ & $1(1.3)$ & $1(1.9)$ & \\
\hline \multicolumn{5}{|c|}{ Influencing factors in the development of breast cancer, $\mathrm{n}(\%)$} \\
\hline Yes & $25(14.9)$ & $24(30.8)^{*}$ & $17(32.1)^{*}$ & \multirow{3}{*}{0.005} \\
\hline No & $143(85.1)$ & $53(67.9)$ & $35(66.0)$ & \\
\hline No data & $0(0.0)$ & $1(1.3)$ & $1(1.9)$ & \\
\hline \multicolumn{5}{|l|}{ Hereditary, n (\%) } \\
\hline Yes & $103(61.3)$ & $44(56.4)$ & $27(50.9)$ & \multirow{3}{*}{0.658} \\
\hline No & $64(38.1)$ & $33(42.3)$ & $25(47.2)$ & \\
\hline No data & $1(0.6)$ & $1(1.3)$ & $1(1.9)$ & \\
\hline \multicolumn{5}{|l|}{ Family history of breast cancer, n (\%) } \\
\hline Yes & $87(51.8)$ & $25(32.1)^{\$}$ & $29(54.7)$ & \multirow{3}{*}{0.019} \\
\hline No & $79(47.0)$ & $53(67.9)$ & $24(45.3)$ & \\
\hline No data & $2(1.2)$ & $0(0.0)$ & $0(0.0)$ & \\
\hline \multicolumn{5}{|l|}{ Knowledge about self-examination, n (\%) } \\
\hline Yes & $33(19.6)$ & $27(34.6)^{*}$ & $19(35.8)^{*}$ & \multirow{3}{*}{0.0001} \\
\hline No & $121(72.0)$ & $51(65.4)$ & $34(64.2)$ & \\
\hline No data & $14(8.3)$ & $0(0.0)$ & $0(0.0)$ & \\
\hline \multicolumn{5}{|l|}{ Signs and symptons, n (\%) } \\
\hline Yes & $27(16.1)$ & $16(20.5)$ & $17(32.1)^{*}$ & \multirow{3}{*}{0.032} \\
\hline No & $132(78.6)$ & $61(78.2)$ & $36(67.9)$ & \\
\hline No data & $9(5.4)$ & $1(1.3)$ & $0(0.0)$ & \\
\hline \multicolumn{5}{|l|}{ Every tumor is cancer, $\mathrm{n}(\%)$} \\
\hline Yes & $104(61.9)$ & $23(29.5)^{*}$ & $20(37.7)^{*}$ & \multirow{3}{*}{0.0001} \\
\hline No & $56(33.3)$ & $46(59.0)$ & $30(56.6)$ & \\
\hline No data & $8(4.8)$ & $9(11.5)$ & $3(5.7)$ & \\
\hline \multicolumn{5}{|l|}{ Breast cancer can be prevented, n (\%) } \\
\hline Yes & $121(72.0)$ & $44(56.4)$ & $37(69.8)$ & \multirow{3}{*}{0.181} \\
\hline No & $35(20.8)$ & $25(32.1)$ & $11(20.8)$ & \\
\hline No data & $12(7.1)$ & 9 (11.5) & $5(9.4)$ & \\
\hline \multicolumn{5}{|l|}{ Medical consultation, n (\%) } \\
\hline When sick & $124(73.8)$ & $45(57.7)^{*}$ & $18(34.0)^{*}$ & \multirow{3}{*}{0.0001} \\
\hline Annually & $34(20.2)$ & $24(30.8)$ & $30(56.6)$ & \\
\hline No data & $10(6.0)$ & 9 (11.5) & $5(9.4)$ & \\
\hline \multicolumn{5}{|l|}{$\begin{array}{l}\text { * } \mathrm{p}<0.05 \text { vs volunteers from exact courses. } \\
{ }^{\mathrm{p}} \mathrm{p}<0.05 \text { vs volunteers from exact and human courses. } \\
\text { } \mathrm{p}<0.05 \text { vs volunteers in the exact and health courses. } \\
\text { n: Number }\end{array}$} \\
\hline
\end{tabular}


Contrary to expectations, despite the majority not having knowledge about the disease, most believe there is a cure for it, which could reflect respondents' knowledge of female breast cancer, suggesting an effective message from campaigns targeted at women. Similarly, more than $55 \%$ of respondents believed that there was a hereditary element in breast CA. It is possible to speculate that respondents in our study are basing their responses on information about female breast CA which has stressed a combination of environmental, hormonal and genetic factors in pathogenesis (13). Data from the Generations Study has shown there is a higher incidence of breast cancer in women who had first-degree relatives with the disease (22). A large cohort study from the United Kingdom of 110,000 women reported that the risk of breast cancer increased considerably based on the number of family cases in terms of age and the national incidence levels of this disease (23).

Still, in our subjects, most were unaware of the existence of selfexamination, and most did not usually go to medical consultations until actually becoming unwell. Once again, this reflects the targeting of campaigns to the female audience, and the scarcity of stimulus for men to protect themselves, as demonstrated in the studies of Alves et al. (24) and Gomes et al. (25), who claimed that men identified and externalized their needs less, as well as the need for assistance and, therefore, seek health services less when compared to women.

The interviewees were grouped according to the area of higher education in pure sciences, humanities and health sciences, in order to carry out analyzes and comparisons between groups. Thus, it was expected that knowledge about male breast cancer would be greater among health sciences students. However, the results showed that knowledge was similar between groups. Still, when analyzing alcohol and cigarette consumption among students, it was higher among health students $(77.4 \%)$, despite these being known risk factors for several pathologies, such as cardiovascular diseases (26). Our data present similar findings to that of Ferraz et al. in which they evaluated 284 undergraduates in medicine, law, and civil engineering, and found a higher prevalence of alcohol and tobacco use among medical students (27).

Finally, an elegant study conducted by Özaydın et al. (28) reported that men who followed women with breast cancer during treatment, still did not have sufficient and accurate knowledge of the disease. These authors correlated higher levels of knowledge about breast cancer with more positive attitudes during the care of women. Thus, the authors suggested that breast cancer awareness activities should include men, in order to increase their knowledge and change their attitudes in a more positive way. Our analysis suggest that there is a directly proportional relationship between maternal education and knowledge of breast cancer, so that the children of better educated women tended to have greater knowledge of the condition. Similar findings have been reported previously when greater knowledge of the relationship between Human Papiloma virus and cervical or penile cancer and also Pap smear in women was identified (29-31).

As a limitation of the study, the authors emphasize that because it is a survey that used a self-completion questionnaire, with no influence from the researchers, it is possible that the volunteers did not understand the questions correctly, and therefore answered incorrectly. Another fact is that by possible knowledge about breast cancer in women, the volunteers may have been influenced to answer the questions about knowing about male breast cancer and whether breast cancer would be curable. Thus, this is made as a possible bias of acquisition, but does not invalidate the evidence that the male population in question needs support in health education, especially breast cancer in men.

In Conclusion these results showed that respondents in this study had limited knowledge about breast cancer in men, as well as its risk factors, forms of self-care and diagnosis, and a deficit in health care follow-up.

Considering the increase in the number of late diagnoses of male breast cancer, and mostly in stages of poor prognosis, these findings suggest that it is important to counter the lack of information about the disease and its signs and symptoms while also providing information concerning the possibility of screening and potential cures. It will be important to undertake further studies concerning men's knowledge of male breast CA, in other and larger populations. In addition, we suggest a need for on-going surveys in order to monitor the effect of better public health information about the condition and to emphasize the importance of early diagnosis, screening and the potential benefits of prompt treatment.

Ethics Committee Approval: This project was submitted to the Research Ethics Committee with Human Beings of the FACTHUS under registration number $05 / 2018$, as well as the use of the free and informed consent term to carry out the project and apply the questionnaires to people as required. Resolution $466 / 2012$ of the National Health Council on ethical issues in research with human participants, from the Ministry of Health of the Federative Republic of Brazil.

Informed Consent: It was obtained.

Peer-review: Externally peer-reviewed.

\section{Authorship Contributions}

Conception: D.R.A., A.L.B.V., J.C.A.; Design: D.R.A., A.L.B.V., J.C.A.; Data Collection and/or Processing: D.R.A., E.H.F., D.K., R.M.S., V.F.M.C., P.P.G.D.R.F., B.S.R.A., Í.M.M.M., M.R.O., A.L.B.V., J.C.A.; Analysis and/or Interpretation: D.R.A., E.H.F., D.K., R.M.S., V.F.M.C., P.P.G.D.R.F., B.S.R.A., Í.M.M.M., M.R.O., A.L.B.V., J.C.A.; Writing: D.R.A., E.H.F., D.K., R.M.S., V.F.M.C., P.P.G.D.R.F., B.S.R.A., Í.M.M.M., M.R.O., A.L.B.V., J.C.A.

Conflict of Interest: The authors declare no conflict of interest.

Financial Disclosure: The research has no financial grants and supports.

\section{References}

1. Global Cancer Observatory. Cancer Today. France: International Agency of Research on Cancer. 2020. Available at: https://gco.iarc.fr/today/home [Crossref]

2. American Cancer Society. Key Statistics For Breast Cancer in Men: Cancer Facts \& Figures 2018. Atlanta: American Cancer Society, 2018. [Crossref]

3. Gucalp A, Traina TA, Eisner JR, Parker JS, Selitsky SR, Park BH, et al. Male breast cancer: a disease distinct from female breast cancer. Breast Cancer Res Treat 2019; 173: 37-48. (PMID: 30267249) [Crossref]

4. Ministry of Health (BR). José de Alencar Gomes da Silva National Cancer Institute. Estimate 2020 - Cancer Incidence in Brazil. Rio de Janeiro: INCA; 2019. p.122. [Crossref]

5. Unadjusted proportional mortality from cancer, Brazil or Region, males, females or males and females, groupCid and by selected year or period. Atlas of Cancer Mortality [Article in Portuguese]. 2018. Available at: https:// www.inca.gov.br/aplicativos/atlas-de-mortalidade-por-cancer [Crossref] 
6. American Cancer Society. Cancer Facts \& Figures 2019. Atlanta: American Cancer Society; 2019. [Crossref]

7. Bray F, Ferlay J, Soerjomataram I, Siegel RL, Torre LA, Jemal A. Global cancer statistics 2018: GLOBOCAN estimates of incidence and mortality worldwide for 36 cancers in 185 countries. CA Cancer J Clin 2018; 68: 394-424. (PMID: 30207593) [Crossref]

8. Ferlay J, Ervik M, Lam F, Colombet M, Mery L, Pińeros M, et al. Cancer today. Lyon, France: International Agency for Research on Cancer, 2018. [Crossref]

9. Stewart BW, Wild CP (eds.). World Cancer Report 2014. Lyon: IARC Press, 2014. p. 1010.

10. Johansson I, Nilsson C, Berglund P, Lauss M, Ringnér M, Olsson H, et al. Gene expression profiling of primary male breast cancers reveals two unique subgroups and identifies $\mathrm{N}$-acetyltransferase-1 (NAT1) as a novel prognostic biomarker. Breast Cancer Res 2012; 14: R31. (PMID: 22333393) [Crossref]

11. Carvalho Neto AC, Nunes GPS, Pereira HFBESA. Epidemiological and clinical profile of men with breast cancer in Amazonas, Brazil. Mastology 2019; 29: 131-135. [Crossref]

12. Silvestri V, Barrowdale D, Mulligan AM, Neuhausen SL, Fox S, Karlan BY, et al. Male breast cancer in BRCA1 and BRCA2 mutation carriers: pathology data from the Consortium of Investigators of Modifiers of BRCA1/2. Breast Cancer Res 2016; 18: 15. (PMID: 26857456) [Crossref]

13. Ministry of Health (BR). José Alencar Gomes da Silva National Cancer Institute. Breast cancer: we need to talk about it. Rio de Janeiro: INCA; 2014. p.18. [Crossref]

14. Salomon MFB, De Mendonça JV, Pasqualette HAP, Pereira PMS, Sondermman VRM. Breast cancer in men [Article in Portuguese]. Braz ] Mastol 2015; 25: 141-145. [Crossref]

15. Hultborn R, Hanson C, Köpf I, Verbiené I, Warnhammar E, Weimarck A. Prevalence of Klinefelter's syndrome in male breast cancer patients. Anticancer Res 1997; 17: 4293-4297. (PMID: 9494523) [Crossref]

16. Al-Naggar RA, Al-Naggar DH. Perceptions and opinions about male breast cancer and male breast self-examination: a qualitative study. Asian Pac J Cancer Prev 2012; 13: 243-246. (PMID: 22502677) [Crossref]

17. Gao Y, Heller SL, Moy L. Male breast cancer in the age of genetic testing: an opportunity for early detection, tailored therapy, and surveillance. Radiographics 2018; 38: 1289-1311. (PMID: 30074858) [Crossref]

18. American Cancer Society. Breast cancer in men. Atlanta: American Cancer Society, 2010.

19. Thomas E. Original research: men's awareness and knowledge of male breast cancer. Am J Nurs 2010; 110: 32-37, 39-40; quiz 41-2. (PMID: 20885124) [Crossref]
20. Robinson JD, Metoyer KP Jr, Bhayani N. Breast cancer in men: a need for psychological intervention. J Clin Psychol Med Settings 2008; 15: 134-139. (PMID: 19104977) [Crossref]

21. De Gutiérrez MGR, De Almeida AM. Pink October. Acta Paulista de Enfermagem 2017; 30: 3-5. [Crossref]

22. Swerdlow AJ, Jones ME, Schoemaker MJ, Hemming J, Thomas D, Williamson J, et al. The Breakthrough Generations Study: design of a long-term UK cohort study to investigate breast cancer aetiology. Br J Cancer 2011; 105: 911-917. (PMID: 21897394) [Crossref]

23. Brewer HR, Jones ME, Schoemaker MJ, Ashworth A, Swerdlow AJ. Family history and risk of breast cancer: an analysis accounting for family structure. Breast Cancer Res Treat 2017; 165: 193-200. (PMID: 28578505) [Crossref]

24. Alves RF, Silva RP, Ernesto MV, Lima AGB, Souza FM. Gender and health: caring for men in debate. Psychology: Theory and Practice 2011; 13: 152-166. [Crossref]

25. Gomes R, Moreira MC, do Nascimento EF, Rebello LE, Couto MT, Schraiber LB. Os homens não vêm! Ausência e/ou invisibilidade masculina na atenção primária [Men don't come! Absence and/or invisibility in primary healthcare services] [Article in Portuguese]. Cien Saude Colet 2011; 16(Suppl 1): 983-992. (PMID: 21503446) [Crossref]

26. Bell S, Daskalopoulou M, Rapsomaniki E, George J, Britton A, Bobak $\mathrm{M}$, et al. Association between clinically recorded alcohol consumption and initial presentation of 12 cardiovascular diseases: population based cohort study using linked health records. BMJ 2017; 356: j909. (PMID: 28331015) [Crossref]

27. Ferraz L, Rebelatto SL, Schneider GC, Anzolin V. The use of alcohol and tobacco among students of a university in Southern Brazil. Rev Bras Promoç Saúde. 2017; 30: 79-85. [Crossref]

28. Özaydın AN, Doğan E, Bozdoğan B. Men's knowledge and attitudes towards breast cancer: a descriptive study. Eur J Breast Health 2020; 16: 183-191. (PMID: 32656518) [Crossref]

29. Cirino FMSB, Nichiata LYI, Borges ALV. Knowledge, attitude and practices in the prevention of cervical cancer and hpv in adolescents. Anna Nery School 2010; 14: 126-134.

30. Abdalla GK, Fajardo EF, Gomes BBM, Bianco TM, Salge AK, Carvalho $\mathrm{EE}$, et al. Analysis of knowledge level in brazilian students about human papillomavirus infection and development of penile cancer. Asian Pac J Cancer Prev 2017; 18: 1371-1376. (PMID: 28612588) [Crossref]

31. Abdalla GK, de Carvalho EEV, Marques KC, Martins MG, Silveira CF, Estevam G, et al. College students' knowledge about human papillomavirus infection [Article in Portuguese]. J Biomed Sci 2015; 2: 50-55. [Crossref] 